\title{
UMA ANÁLISE DO LEGADO AUTÓCTONE NA EDUCAÇÃO CUBANA.
}

\author{
Maria do Carmo Luiz Caldas Leite ${ }^{1}$
}

\begin{abstract}
RESUMO
presente texto está vinculado à pesquisa que buscou investigar a influência do legado autóctone nos processos educativos em Cuba, acumulados desde os séculos da colonização, e compreender a formação do professor como militante político, dentro da experiência que consolidou as bases do projeto societário cubano atual, no qual a elevação cultural caminha junto às lutas contra a dominação estrangeira. Os registros desta pesquisa resultam das investigações de campo nas escolas em Cuba, entre 2001 e 2013, de contatos com a população cubana, da participação em congressos nas diversas províncias do país e, finalmente, da apreciação crítica de estudos embasados na interface entre história e educação, assim como nas transformações para o enfrentamento dos atuais problemas do país.

Palavras-chave: educação em Cuba; legado pedagógico; escola no socialismo.
\end{abstract}

\section{AN ANALYSIS OF AUTOCHTHONOUS HERITAGE IN THE CUBAN EDUCATION}

\begin{abstract}
This text is about a research that investigates the influence of autochthonous heritage in educational processes in Cuba, accumulated from centuries of colonization to the challenges currently faced as well as understand the formation of teachers as a political activists within the experience that consolidated the basis of the current Cuban social project, in which the cultural elevation is accompanied by the resistance against foreign domination. The records of this research result from field investigations in Cuban schools between 2001 and 2013, contacts with the Cuban population, participation in conferences in various provinces of the country and finally the critical review of studies grounded in the interface between history and education.
\end{abstract}

Keywords: education in Cuba; pedagogical legacy; school in socialism.

\section{Antecedentes históricos: a sociedade formada por retalhos}

El mundo tiene dos campos: todos los que aborrecen la libertad, porque sólo la quieren para si, están en uno; los que aman la libertad, y la quieren para todos, están en otro $^{2}$.

José Martí

Em Cuba, um peculiar processo histórico, semelhante ao da maioria das Antilhas, fez com que concorressem para a formação do espírito nacional dois fluxos: o espanhol, dos conquistadores, e o africano, dos escravos. Nas palavras de Augier, (2001, p.5), "uma profunda tarefa de séculos caracterizada por mesclas de diferentes sangues, tradições, sonhos e conflitos, coagulou a sociedade cubana". 
O enriquecimento dos colonizadores apoiou-se na submissão imposta aos nativos, interrompendo o processo autônomo das comunidades indígenas e inserindo em Cuba o regime de servidão feudal. Os imigrantes traziam consigo a mesma cadeia de subordinações sociais. Os registros da sociedade produzida pelo açúcar e a história da escravidão tem interfaces de séculos com profundas marcas na sociedade cubana. De acordo com Buenavilla Recio (1995a, p.3), "se com sangue e suor dos negros escravos construíram-se as grandes fortunas dos latifúndios, com seu espírito de rebeldia semeou-se o caminho da independência". A cubanía ${ }^{3}$, de raiz afro-espanhola e de vocação latinoamericana, promoveu os combates pela independência. Após três décadas de lutas iniciadas por Céspedes ${ }^{4}$ e revitalizadas de forma pujante por Martí ${ }^{5}$, no ano de 1895 , o colapso do colonialismo na ilha era iminente. Havia chegado a hora de "encarnar a ação e a história do ethos patriótico, iluminado pela poesia e pelo pensamento cubano" (VITIER, 2011, p.42). Entretanto, a violência dos conquistadores não anulou as marcas de autoctonia na cultura e no caráter dos cubanos, uma vez que "com seu espírito de rebeldia se semeou o caminho da independência” (BUENAVILLA RECIO, 1995b, p. 3).

Em uma das mais belas imagens, o poeta que Marx levava dentro de si escreveu que a violência é a parteira da história. O expirar do século XIX foi marcado pela Guerra Hispano-Americana. Com o fim das hostilidades, a chamada Emenda Platt oficializou o direito a novas intervenções militares e autorizava o governo dos Estados Unidos a arrendar terras necessárias às bases navais. Foi assim que a Baia de Guantánamo ficou sob o controle estrangeiro até os dias de hoje. Em 1898, o poder militar norte-americano interveio em Cuba, impondo aos insurgentes uma amarga experiência. Uma das primeiras preocupações do governo interventor foi a dissolução do Exército $M a m b \imath^{6}$, que permanecia em armas nos campos. O povo foi arrastado à profunda miséria, pois a luta contra $\mathrm{o}$ colonialismo não culminou com a vitória. A vivência dos escravos, que lutaram não apenas pela independência de Cuba, como pela própria emancipação, assim como dos milhares de camponeses que se uniram às fileiras do exército mambí em busca de justiça social, distanciava-se muito do modo de vida das elites, que mediante a guerra tentaram libertar-se do domínio metropolitano, sem perder seus privilégios de classe, nem sua posição de dirigentes do projeto nacional. Martí (2011a, t.17, p.328), refere-se aos "homens cautelosos que queriam gozar da liberdade, sem pagar o seu sangrento preço".

\section{A pedagogia na sociedade do açúcar}

Puesto que a vivir viene el hombre, la educación ha de prepararlo para la vida. En la escuela se ha de aprender el manejo de las fuerzas con que en la vida se ha de luchar (MARTÍ, 2011b, p.9).

A ocupação de Cuba estendeu-se até 1902 e consolidou a reorganização de um sistema político em função de interesses neocoloniais. Nesse bojo, a influência estrangeira significou a interrupção, entre outras questões, do legado pedagógico dos pensadores cubanos, desenvolvido nos séculos anteriores. O estudo da sociedade cubana aponta à acumulação de riquezas vinculadas aos signos da aristocracia ibérica. Entretanto, sem um sistema escolarizado, onde apenas parte ínfima da população recebia algum ensino nos centros urbanos da época, Cuba foi a última colônia da Espanha nas Américas. Durante mais de quatro séculos a maioria da população esteve excluídas do acesso à educação e à cultura, sob um regime que sustentou a degradante instituição do trabalho escravo e governou com "um braço de ferro ensanguentado", como disse Céspedes, o Pai da Pátria (CUBA, 1999, p.7). 
Precursor da tradição pedagógica progressista na ilha, o sacerdote José Agustín Caballero foi uma das importantes figuras da Ilustração Reformista criolla no final do século XVIII, o movimento de ideias que se vinculou à ampliação do setor açucareiro. No ano de 1794, Caballero apresentou um projeto caracterizado por métodos anti-escolásticos para a criação de escolas elementares públicas, razão pela qual é considerado "o introdutor em Cuba do sistema em que o aluno poderia desenvolver um pensamento organizado e uma aprendizagem mais sólida" (BUENAVILLA RECIO, 1995a, p.8).

Em meados do século XIX, o ideólogo independentista e sacerdote católico Félix Varela, defensor da ilustração do povo como exigência social, foi o primeiro a assumir entre os educadores cubanos uma atitude radicalmente revolucionária, em especial na crítica ao modelo escravista. Mais do que demandas estreitas e imediatas, o sacerdote aspirava, ao registrar as vicissitudes de sua época, a emancipação da sociedade e a educação patriótica, expressando suas ideias nos marcos da liberdade cristã, pois para ele as potencialidades que existem no homem o conduzem, infalivelmente, pelos caminhos do bem e do saber, quando dirigidos corretamente. Como salienta Buenavilla Recio (1995b, p.8), "na concepção de Varela, estudar não era devorar livros; haveria que analisar, compreender e meditar".

A escola cubana foi renovada em seus métodos por José de La Luz y Cabarello, discípulo de Varela, que como professor, entre 1824 e 1862, contribuiu para desenvolver a pedra angular de uma escola destinada às necessidades do país e à formação moral dos jovens. Para Buenavilla Recio (1995a, p. 12), Luz y Caballero tinha uma percepção ampla do processo educativo, que não deveria restringir-se ao ato de instruir, mas centrar-se no cultivo dos sentimentos. Nesse contexto, para a classe dos incapazes economicamente, existiam as escolas eclesiásticas e as "escolinhas de amigos e amigas", as primeiras de base social popular em Cuba. Os professores não tinham preparo adequado, nem licença para ensinar, ocupando uma posição marginal na sociedade. Entretanto, nelas se praticava, de maneira incipiente, a integração racial e as manifestações iniciais de coeducação entre meninos e meninas.

A história da pedagogia cubana, por mais breve e concisa, não poderia ser escrita sem referências ao papel desempenhado por José Martí. Na expressão de Baralt (1990, p.1), "ninguém enganchou seu carro a uma estrela, com mais firme propósito de alcançar uma meta do que o apóstolo nacional de Cuba". Para ele, a vida era luta em perene aperfeiçoamento. "Todo hombre nace rey; la labor está en hallar en sí los útiles con que se hace el trono". (MARTÍ, 1975, t.9, p.339)

O fato do ideário martiano, impregnado de humanismo, privilegiar valores, tornouse evidente em1889, quando da publicação do primeiro número de La Edad de Oro, revista voltada às crianças do continente latino-americano. Nessa obra, escrita e editada por Martí, surge a proposta de criar nos meninos de Nuestra América - ameaçados pela progressiva perda de sua identidade cultural - uma consciência anticolonialista e um alto sentido de solidariedade humana. Como professor, ganhou a vida nas fases mais difíceis, mas não foi pedagogo no sentido estrito do termo, pois sua profissão foi a de advogado. Segundo Vitier (2011), o jornalismo, conjugado à política, ocupou grande parte de suas atividades, consagrando Martí como uma pessoa de firmeza na expressão, atento aos problemas da educação e comprometido com a justiça, que soube vincular a beleza ao verso e à prosa. A trajetória de sua vida revolucionária o fez passar por vários países, proporcionando-lhe conhecimentos avançados para seu tempo. Na concepção martiana, era grave a escola seguir os padrões de sistemas forâneos, desvinculados das realidades socioeconômicas em que se aplicavam, reafirmando a busca de uma legítima cultura ajustada à realidade latino-americana, livre da dominação de teorias importadas da 
América Anglo-saxônica, ainda que alimentasse a ideia da abertura de Cuba ao mundo. Martí possuía um referencial teórico - que evoluiu historicamente -, no qual a educação é concebida como uma estratégia para o desenvolvimento do homem. Nesse sentido, avaliou os estreitos limites da corrente positivista vigente na América Latina na segunda metade do século XIX, "defendendo sua própria concepção educativa integral e multifacetada, que ultrapassava as fronteiras do utilitarismo e as caricaturas de ideias de outras latitudes" (CHÁVEZ RODRÍGUEZ, 1996, p.36).

Como estudioso não apenas dos problemas da instrução, mas da realidade do continente americano, onde teve a oportunidade de viver, Martí elaborou um pensamento pedagógico, com a urgência da sonhada República em Cuba. Ao diferenciar instrução de educação e destacar o processo dialético entre as categorias pedagógicas, Martí defendeu o princípio de que não há boa educação sem instrução. Era necessário instruir e orientar, porém, ao mesmo tempo, era imprescindível dirigir os sentimentos. A vigência de seu ideário - à parte de sua inserção na história política e literária de nosso continente -, "radica no sabor de testemunho e na capacidade de indignação diante da injustiça", de acordo com Augier (1961, p. 14).

Na alvorada do século XX, Enrique José Varona, um crítico denunciante dos males que arquejavam a República, empreendeu reformas educacionais que refletiram no ensino científico e experimental em Cuba. Nesse período, observou-se uma marcada penetração de ideias norte-americanas, de acordo com o interesse dos interventores. Em relação ao papel do professor e dos métodos de ensino, Varona sustentou a linha de Martí ao afirmar:

O professor deve estudar, para que saiba ensinar a estudar. O que esteriliza a educação é o dogmatismo, que pretende economizar o trabalho do aluno e lhe dá fórmulas, em vez de despertar seus estímulos para que saiba chegar a elas (COLETIVO DE ESPECIALISTAS ICCP, 1984, p.8).

Varona acreditava que com homens dogmatizados seria impossível promover a transformação social que demandava o país, dentro de um pensamento que privilegiasse os métodos científicos aplicados à educação. Para ele convinha aos escolares "ler menos e observar mais, comparar mais, meditar mais, experimentar mais, em uma palavra: interrogar mais a natureza e ouvir menos o professor" (BUENAVILLA RECIO, 1995a, p. 22).

De acordo com Pogolotti (1995, p. 5), durante a República começou a produzir-se paulatinamente a recuperação da imagem de Martí, que cresceu através da transmissão oral vivenciada pelos herdeiros do frustrado projeto independentista. $O$ ideário de Martí manteve-se na palavra cotidiana dos professores, que inscreveram na memória das crianças os versos martianos. Juntos a eles levantou-se a figura do herói e com essa recordação viva realimentaram-se a utopia e os sonhos de independência.

$\mathrm{O}$ século XX chegou a Cuba com um conjunto de imposições econômicas, políticas e sociais, decorrentes da primeira intervenção militar dos Estados Unidos no país. O triunfo da Revolução Socialista, em 1917, segundo Buenavilla Recio (1995a, p.87), repercutiu em toda a América Latina. Entre as consignas dos trabalhadores, surgiram novas vinculações das teorias revolucionárias às lutas no continente. Durante as décadas de 20 a 40, na república mediatizada cubana, constatou-se a existência da uma luta ideológica e política, entre duas tendências pedagógicas contrapostas: de um lado, a democrática e progressista, que representava os interesses do povo, e, do outro, a corrente reacionária, das classes dominantes. 
No início da década de 30, observa-se uma acelerada penetração na economia cubana de grupos estrangeiros. Na visão crítica de Cirules (1994, p.16), a capital cubana ofereceu-se à máfia norte-americana como "o mais esplendoroso dos paraísos", com o turismo e os jogos ilegais organizados. Esse tipo de negócio cresceu de tal maneira que Cuba era considerada um importante centro da delinquência internacional. A situação econômica da ilha era típica de um país agrário atrasado, onde coexistiam relações précapitalistas e relações capitalistas, baseadas no capital monocultor, monoexportador e atado às necessidades econômicas dos vizinhos ao norte.

Tabares del Real (1989, p.12) salienta que os professores cubanos forjaram nas novas gerações os ideais de soberania nacional e o rechaço à opressão, em concomitância com as péssimas condições de trabalho. A política da oligarquia criolla, a partir da crise globalizada do modelo neocolonial, apresentou muitas facetas, porém estas se basearam principalmente em restringir a produção agrícola e industrial à esfera açucareira, mediante a cartelização.

\section{As transformações que afetaram os processos sociais em Cuba após 1953}

Educar es depositar en cada hombre toda la obra humana que le ha antecedido; es hacer a cada hombre resumen del mundo viviente hasta el día en que vive: es ponerlo a nivel de su tiempo, para que flote sobre él (MARTÍ, 2011a, t. 18, p.228).

Na alvorada de 26 de julho de 1953, o assalto ao Quartel Moncada, em Santiago de Cuba, sob o comando de Fidel Castro, inaugurou um novo período na ilha. O centenário natalício de Martí retratava um quadro de desmandos financeiros e desatenção em relação aos serviços educacionais. De acordo com os dados do Ministério da Educação (CUBA, 1999, p.9):

- Apenas $56,4 \%$ das crianças podiam frequentar a escola primária e somente $28 \%$ dos jovens continuavam os estudos de ensino médio.

- Para a formação de professores, havia um número restrito de seis escolas normais oficiais e só existiam três Faculdades de Educação, vinculadas às Universidades de Havana, de Las Villas e do Oriente.

- Em todo o país, havia mais de meio milhão de crianças sem escola e um milhão de analfabetos.

A radicalização socialista dos anos de 1960 transformou esse dinamismo por meio de um novo posicionamento crítico sobre a própria América e seu lugar na história. Os anos de reflexão sistemática sobre a condição dos americanos produziram toda sorte de interpretações em torno da identidade cultural de Nuestra América. "Desviada em seu desenvolvimento, as dificuldades não puderam anular, como demonstrou o processo iniciado em Moncada, a tradição de lutas que vinha do século XIX" (HART DÁVALOS, 2005, p.142).

A primeira etapa da Revolução acarretou mudanças que estabeleceram novos fundamentos educacionais. O grande desafio foi a alfabetização, cujos passos iniciais ocorreram no período da luta insurrecional, a partir 1956, quando os guerrilheiros em Sierra Maestra deveriam ser, além de combatentes, difusores da cultura e do conhecimento, produzindo um fluxo entre as necessidades do trabalhador rural e as preocupações em âmbito nacional e internacional. "Las revoluciones son estériles, cuando no se firman con la pluma en las escuelas y con el arado en los campos" (MARTÍ, 1975, t.7, p.163).

Revista HISTEDBR On-line, Campinas, $n^{o}$ 59, p.318-332, out2014-ISSN: 1676-2584 322 
Os movimentos alfabetizadores, trazendo dimensões de epopeia, constituíram uma fonte motivadora, que iriam transformar social e economicamente a nação. Como afirma Vitier (2011, p.212), "a pátria que estava nos textos, na paixão de seus fundadores, subitamente encarnou, quando um raio de justiça colocou cada qual em seu lugar exato". No momento em que as massas de "los de abajo", que Rodríguez Rivera (2005, p.109) compara aos "pobres de la tierra" ", obteve posições de destaque foram promulgadas as primeiras medidas, modificando de forma radical as estruturas em Cuba. Os muros dos quartéis, vistos como ponto de partida das tropas opressoras e centros de tortura, foram derrubados para dar espaços às salas de aula no interior das antigas fortalezas. A Ciudad Libertad, até 1959 o Colúmbia, uma típica instalação militar, foi transformada em amplo conjunto com escolas de ensinos primário, secundário, especial e superior. Nesse contexto, revestiu-se de transcendência política e moral a conversão de 69 quartéis em escolas com capacidade para 40 mil alunos. Em 9 de janeiro de 1960, como salienta Hernández Pardo (1974, p. 51), foi iniciada a demolição dos muros por centenas de operários da construção, estudantes universitários e contingentes da população, que converteram o sombrio quartel Moncada na Ciudad Escolar 26 de Julio, em apenas 19 dias.

A lei que estabelecia a primeira Reforma Integral do Ensino, promulgada ainda em 1959, adotou um novo objetivo fundamental para a educação, de acordo com os interesses da Revolução Cubana, que segundo o Ministério da Educação (CUBA, 1999, p. 7), é o pleno desenvolvimento humano. A busca do homem novo ${ }^{8}$, pela reapropriação da natureza humana, tornou-se o centro de mobilização da sociedade, que pensava em converter-se numa grande escola. "Depois da revolução cubana deu-se máxima prioridade à educação e à saúde para fomentar o desenvolvimento humano" (UNESCO, 2005, p. 57).

As profundas reformas na estrutura econômica, política e social de Cuba buscavam implementar a ruptura de poder do Estado burguês. A criação das bases de um novo modelo tentava transformar a saúde, a educação e a cultura em direitos para toda a população. A meta mais ambiciosa foi a erradicação do analfabetismo em 1961, o "Ano da Educação". A Campanha Nacional de Alfabetização - reflexo do pensamento autóctone teve seus antecedentes na época do colonialismo espanhol, quando o exército dos mambises vinculou a aprendizagem da escrita e da leitura à formação dos valores patrióticos. Em 1896, com a publicação El cubano libre editou-se "a primeira cartilha voltada ao desenvolvimento de uma consciência participativa na vida político-social do país", segundo Canfux Gutiérrez (2006, p.1).

A relação que estabelecera Martí, em 1884, entre cultura e emancipação - "ser culto é o único modo de ser livre" (MARTí, 2011b, p.52) -, complementada com os pressupostos do movimento 26 de julho, serviu de base para a concepção de um sistema de educação orientado por novos fundamentos. A campanha desencadeou-se com o chamamento de voluntários para a tarefa de alfabetizar. Participaram milhares de estudantes, operários, alfabetizadores populares e professores, o que possibilitou a criação de documentários, poesias, canções e análises dos interessados em compreender as razões que ensejaram a mobilização das massas de forma organizada. Analisando-a em sua dimensão mais abrangente, pode-se dizer que o objetivo maior foi conseguido: tirar a população da inércia habitual e mobilizá-la coletivamente, transformando antigos traços culturais de acomodamento em relação à ação paternalista das autoridades.

Esta experiência configurou-se como o primeiro grande vínculo da educação à vida política, pois os alfabetizadores, participando de tarefas comuns, como arar, compreenderam as desigualdades sociais e conscientizaram-se da necessidade de superação dos graves problemas que afetavam o país. Eles deram um passo à frente e tornaram real a ideia de Martí $(1975$, t. 12, p.375), que "ao vir à Terra todo homem tem 
direito à educação, e, depois, em pagamento, o dever de contribuir com a educação dos demais. Na cartilha Alfabeticemos, o governo conclamava os alfabetizadores a "defender a soberania dentro dos princípios de unidade incorruptível" (COMISIÓN NACIONAL DE ALFABETIZACIÓN, 1961, p.5).

Os professores emergentes contribuíram para a consolidação do papel das organizações de massa no país e seu trabalho constituiu um estímulo à criação de novas instituições na sociedade civil. Em 22 de dezembro de 1961, Cuba foi declarada "Território Livre do Analfabetismo", data em que se comemora o dia nacional dos professores. Dois fatos marcantes ocorreram neste ano. Um deles foi o assassinato do jovem Conrado Benítez, do primeiro contingente de voluntários na Serra de Escambray, por um grupo armado de contrarrevolucionários. Meses depois, com apenas 16 anos, Manuel Ascunce foi torturado e morto. Muitos foram os exemplos da conduta dos adolescentes, pois a maioria dos brigadistas aprendeu a compartilhar necessidades com os camponeses, a enfrentar a vida e também a morte. Os alfabetizadores, indignados, reafirmaram sua decisão de "não ceder nem um passo à incultura", nas palavras de Nuñez Machín (2005, p. 48).

O governo colocou a escola no centro das atenções, ao depositar na educação suas expectativas de transformar a vitória militar do Movimento de 26 de julho em vitória política, como parte da batalha pelos valores considerados fonte de emancipação social e econômica. A campanha de alfabetização, da década de 60, significou, mais que uma estratégia de política educacional, uma experiência profunda que consolidou as bases do projeto societário cubano, no qual a elevação cultural caminhou junto com as lutas contra a dominação estrangeira. Para viabilizar a superação das dicotomias existentes recorreu-se a formação do ser humano em uma perspectiva abrangente, segundo o marxismo, fundamentada no tripé básico da educação para todos, que corresponderia ao ensino intelectual (cultura geral), desenvolvimento físico (ginástica e esporte) e aprendizado profissional polivalente (técnico e científico).

Com o término do movimento de alfabetização e da solidificação das relações com a então URRS, a influência pedagógica de Makárenko foi sedimentada nesse complexo momento da história cubana. Nas diversas etapas do processo revolucionário foi necessário recorrer a políticas de formação intensiva, com incorporação imediata dos professores à prática, como ocorreu em 1969, na campanha "Yo seré maestro". O novo modelo educacional buscou dar respostas aos impasses, com o denominado Ativismo Pedagógico, que perpassou toda década de 60, com base na ideia de que quem sabe mais, ensina quem sabe menos. Entretanto, muitas das soluções imediatistas vigentes nesse período precisaram ser reformuladas. A formação de professores transitou por diferentes etapas a partir de 1964, quando foram fundados os Institutos Superiores Pedagógicos, com o objetivo de dar resposta à necessidade crescente de docentes para o nível médio.

Para Piñeiro Suárez et al. (2006), a pedagogia socialista em Cuba é a manifestação das formulações do marxismo-leninismo em matéria de humanismo e da elevação da capacidade intelectual do homem. Nesse contexto, as relações inerentes ao ato educativo fundamentam-se no conceito do estudante como um ente ativo e na relação professoraluno, mediatizada pela concepção dialética que a lógica do estudante não tem que ser a lógica do professor. Os seus fundamentos são fortemente influenciados pelo ideário pedagógico de Martí, pelos princípios de Luz y Caballero, Varella e Varona, pelas contribuições teóricas de Marx e Engels sobre o trabalho e o coletivismo, acrescidas das formulações dos soviéticos Makárenko ${ }^{9}$ e Vigotski ${ }^{10}$, em conformidade com desenvolvimento sócio-histórico do homem, manifesto pelas necessidades geradas em cada época. 
Makárenko (1982, p. 2) apontava o caminho de formação dos professores fundamentado no invento de um homem novo, construído de maneira nova, pela necessidade de dar não só instrução aos pedagogos, mas também de educá-los. O método por ele criado foi uma novidade no tocante à organização da escola como coletividade e nas ponderações que levavam em conta os sentimentos dos alunos na busca pela felicidade, dentro da concepção solidária do bem-estar coletivo. Queria formar crianças capazes de dirigir a própria vida e os destinos do país. Exercícios físicos, trabalhos manuais, recreação, excursões, aulas de música e idas ao teatro faziam parte do cotidiano nos centros educacionais. A escola deveria favorecer o contato com a sociedade e com a natureza, ou seja, ser um lugar para o jovem viver a realidade concreta e participar das decisões, dentro dos fundamentos do socialismo.

No livro Poema Pedagógico, as concepções de Makárenko afloram como as de um educador aberto, porém rígido. Nele, a idéia do coletivo surgia como respeito a cada aluno, oposta à visão de massificação que despersonalizava a criança. Para a vida em comunidade bem-sucedida, era essencial que cada aluno tivesse clara sua responsabilidade, pois acreditava que o planejamento e o cumprimento das metas estabelecidas por todos só eram possíveis com uma direção firme. Por isso, os alunos tinham consciência de que a disciplina não era um fim, mas um meio, visando o sucesso da vida na escola, e um recurso para vencer as dificuldades. O descumprimento de uma norma podia ser punido severamente, desde que alunos e professores assim o desejassem, depois de muita discussão. "Se por temor ao fracasso não se propõe ao jovem uma tarefa difícil, isso significa dizer que ele com certeza irá fracassar" (MAKÁRENKO, 1982, p. 23). A crença no valor da participação levou o educador ucraniano a questionar a fraca presença dos pais, estimulando-os à integração em atividades culturais e recreativas promovidas pelos centros escolares. Como recorda Labarrere Reyes (2002, p. 131), segundo Makárenko, pais muito "melosos" ou ausentes seriam incapazes de educar uma pessoa para ser forte, madura e inteligente, pois "o carinho, como o jogo e a comida, exige certa dosagem".

O método científico proposto por Vigotski caracteriza-se pela busca das interrelações funcionais mais significativas do processo de desenvolvimento humano: o externo e o interno, a cooperação educador-educando, a relação ensino-aprendizagem, o vínculo desenvolvimento atual-desenvolvimento proximal, a unidade do cognitivo e do afetivo, a relação dos conceitos espontâneos e dos científicos, ou seja, sua estratégia de pensamento, dialética por essência, aborda o estudo dos fenômenos em suas contradições, em sua complexidade (FARIÑAS LEÓN, 2004, p. 41).

Diante da possibilidade de reduzir o processo educativo a uma questão exclusivamente de eficiência técnica, insuficiente no enfrentamento das necessidades do mundo atual, impõe-se a necessidade de formar um sujeito ativo, transformador e crítico, para o qual a educação em Cuba busca seus fundamentos no modelo histórico-cultual de Vigotski. Como García Ramis (2004, p. 19) observa:

Para Vigotski, a aprendizagem é uma atividade social e não somente um processo de realização individual, como até o momento se havia sustentado; uma atividade de produção e reprodução do conhecimento. $\mathrm{O}$ desenvolvimento psíquico da criança tem um caráter histórico concreto de acordo com o nível de desenvolvimento da sociedade e as condições de sua educação. Com base nessa idéia, ele formulou sua teoria sobre a zona de desenvolvimento proximal.

Da perspectiva vigotskiana emana uma acentuada aproximação com a epistemologia dialética materialista, na qual o homem é concebido como sujeito ativo que 
cria o seu meio e a sua realidade, sendo simultaneamente produto desse entorno. Nos processos dialéticos, o sujeito do conhecimento não tem um papel contemplativo diante das mudanças, mas é, sobretudo, estimulado pelo mundo exterior, internalizando conceitos, valores e significados construídos no decorrer histórico, com seus conflitos e contradições. Esse modelo tem incidência na teoria e prática pedagógica em Cuba, posterior a 1959. Atendendo aos aspectos examinados da escola num contexto histórico-cultural, algumas conclusões, acerca da relação dialética existente entre educação, aprendizagem e desenvolvimento do ser humano, são destacadas por Castellanos Simons (2001, p. 20):

\begin{abstract}
Aprender supõe a passagem do externo para o interno -do interpsicológico ao intrapsicológico - da dependência do sujeito à independência, da regulação externa à auto-regulação. Supõe, em última instância, seu desenvolvimento cultural, ou seja, o percurso de um domínio progressivo e a interiorização dos produtos da cultura e dos instrumentos psicológicos que garantem ao indivíduo uma crescente capacidade de controle e transformação sobre seu meio e sobre si mesmo.
\end{abstract}

\title{
Uma concepção de escola para o século XXI
}

Hay injusticia en pedir a una época de aurora todo el vigor y claridaded del día.

José Martí

Em 1995, na vigência Período Especial ${ }^{11}$, como resultado das contradições surgidas no âmbito da educação, abordou-se a possibilidade de um novo modelo para a escola cubana, como parte do projeto La Sociedad Cubana: Retos ante el Siglo XXI. De acordo com Hernández Herrera (2005, p. 7), quando da organização do Sistema de Ciencia e Innovación Tecnológica, no Mined, finalizando o curso escolar de 1995-1996, a situação da atividade científica em Cuba apresentava um conjunto de deficiências relacionadas à falta de uma gestão educativa integrada, de modo que as instituições elaboravam seus próprios planos independentes, com uma quantidade significativa de temas pesquisados, ocasionando a dispersão do potencial científico no país. Em muitos casos não se investigavam os problemas prioritários, o uso dos resultados para tomada de decisões era limitado e predominava um enfoque unidisciplinar.

Sob o impulso desencadeado pelas reuniões internacionais, como a Conferência Mundial sobre Educação para Todos, realizada em Jomtien, em 1990, abriram-se espaços para promover renovações. Os eixos dinamizadores do cambio centravam-se na formulação de políticas educativas, na descentralização dos sistemas, na transformação dos estilos de gestão, no fortalecimento da autonomia, na introdução das novas tecnologias de comunicação e no aperfeiçoamento da profissionalização dos docentes, entre outras (HERNÁNDEZ HERRERA, 2005, p. 2).

Os estudos elaborados pelo ICCP, a partir de 1999, reconheceram que os impactos das transformações sociais, econômicas e culturais, no início deste século, suscitavam a reavaliação do papel da escola e dos professores. Por mais que as instituições escolares tenham sido afetadas em sua estrutura organizacional, nos seus conteúdos e métodos, elas se apresentam constantemente como o principal alicerce do processo revolucionário cubano.

De acordo com Rojas Arce (2005, p. 5), no período letivo de 1999-2000, a direção do Mined empreendeu um processo de transformações, priorizando o fortalecimento da interdisciplinaridade. A educação cubana, nas circunstâncias configuradas em 2000, 
assumiu a tarefa de implementar programas, visando elevar a cultura geral, inseridos em uma revolução técnico-científica, assim como em ações para minimizar o impacto nocivo da globalização neoliberal. Para García Ramis (2005, p. 1), isso se concretizaria na formação de um cidadão consciente dos complexos problemas que afetavam a própria existência da espécie humana e do mundo, na necessidade de uma sólida identidade nacional, na defesa do socialismo e da ética enraizada no pensamento martiano e marxistaleninista, nos elevados níveis de espiritualidade, bem como do pensamento dialético que garanta uma ação criativa e transformadora.

Em dezembro de 2001, os residentes da capital começaram um esforço para restaurar e mobiliar totalmente 734 escolas primárias e secundárias, reconstruir doze, que estavam abandonadas, e construir 33 novas, implementando-se salas de aula necessárias ao novo programa. Cerca de 22 mil construtores profissionais, constituídos a maioria por operários microbrigadistas, apoiados por milhares de voluntários - que incluíam homens e mulheres de todas as profissões, professores, estudantes, crianças, adolescentes, jovens, e até pessoas da terceira idade. A partir de julho de 2002, com a criação da Dirección de Ciencia y Técnica (DCT), implementaram-se importantes mudanças para garantir a orientação e direção da Política Científica e Tecnológica, fundamentada no espírito de integração de todos os elementos do sistema (HERNÁNDEZ HERRERA, 2005, p. 2).

As condições internas configuradas para o novo milênio que determinaram a necessidade de cambios, resultantes de inúmeros estudos coletivos do ISP "Varona" e do ICCP, elaborados pelo Ministério de Educação, foram assim expressas por Diaz Fuentes (2005, p. 4):

- Ruptura entre o modelo de escola e a nova realidade do país.

- Desarticulação entre caráter geral, politécnico e laboral da educação.

- Manifestação de uma escola tradicional, com tendências à reprodução de conhecimentos e não reflexibilidade.

- Conselhos de escola que nem sempre conseguiam desencadear, de forma coerente, o processo educativo nos pais e na comunidade.

- Falta de aplicação coerente das novas tecnologias educativas.

- Dicotomia entre instrução e educação em detrimento da última.

$\mathrm{Na}$ busca de soluções aos problemas arrolados, uma equipe do ISP "Enrique José Varona", em Havana, destacou as idéias básicas, de acordo com Rojas Arce (2005, p. 5):

Ênfase na intencionalidade ideológica do processo formativo, como um imperativo histórico-concreto da sociedade cubana.

$>$ Orientação integradora na prática formativa da escola, fortalecida, entre outros fatores, por uma integração do conteúdo escolar, em um processo de interdisciplinaridade.

$>$ Identificação dos principais problemas sociais, incluídos os inerentes às ciências e à tecnologia, aos quais a escola deveria dar resposta.

Nas últimas décadas tem sido introduzida na escola cubana, em diferentes níveis de ensino, a tecnologia educativa. Para o início do ano escolar de 2003-2004, os programas de computação beneficiavam cem por cento das matrículas com 46.290 computadores instalados em escolas de educação básica, incluídas as rurais, para o que foi necessário eletrificar com coletores solares 2.368 escolas. Enquanto a tendência generalizada no mundo é tentar produzir mudanças mediante planos de estudo, programas e manuais didáticos, nas escolas cubanas os professores converteram-se em educadores responsáveis pela formação integral de um número determinado de alunos que, por sua vez, serão capazes de empregar com efetividade a televisão, o vídeo e a computação no processo de 
aprendizagem, o que representa uma "mudança transcendental" (GÓMEZ GUTIÉRREZ, 2005, p. 7).

As novas tecnologias de informação propiciaram uma revolução em que se mesclam a informática e os canais educativos da televisão, com acentuada força nas imagens. As novas tecnologias comandam cada vez mais a trajetória da comunicação educativa e a relação interpessoal do ensino, como formas de melhorar a interação. Entretanto, nas conclusões de Leal García (2004, p. 88):

A análise das observações, diretamente na escola, demonstrou o impacto da programação televisiva para elevar a qualidade do processo docente educativo, basicamente no tocante aos elementos relacionados à qualidade de diversas fontes de conhecimentos utilizados. Não obstante, constataram-se algumas dificuldades, pois nem todos os professores conseguiram o mesmo nível de aproveitamento das teleclasses, para desenvolver um ensino problematizador, integrado às demais formas de conhecimentos.

As reformulações atuais levam em conta a política educativa traçada pelo Partido Comunista Cubano em seus congressos e pelo estado, para o aperfeiçoamento do Sistema Nacional de Educação. A escola atual cubana, como "uma instituição socializadora por excelência tem um compromisso permanente com a sociedade para formar jovens comprometidos com a continuidade histórica e defesa dos valores do socialismo" (VALLE LIMA, 2013, p. 10).

Este processo de socialização requer uma ação hormônica e coerente com a família - a primeira instituição socializadora do ser humano -, com os grupos sociais entre os quais o estudante se desenvolve, incluídas as organizações de massa pioneril ou estudantil.

Para lograr um trabalho educatico efetivo em cada educando, a escola tem que partir do reconhecimento das condições existentes em cada comunidade onde a instituição de ensino se encontra, de onde os alunos provém, para conhecer como pensam e como se comportam, que ajuda podem necessitar e quais as potencialidades da comunidade (ibid., p. 12)

Considerando que a partir do curso escolar de 2010 - 2011 nas universidades de Ciências Pedagógicas em Cuba se iniciou a formação docente para a educação fundamental e média mediante um perfil de dupla especialidade concebe-se agora um novo tipo de professor que desenvolverá seu trabalho segundo sua orientação profissional: Matemática Física, Español - Literatura, Educação Laboral - Informática, Biologia - Geografia, Química - Biologia e Marxismo Leninismo - História. Além disso, estão mantidos os professores de Inglês, Educação Física e Educação Artística em suas especialidades.

As palavras de Velàzquez Cobiella $(2013$, p. 3) resumem as perpectivas atuais da Educação cubana:

Preparar para a vida é, realmente, preparar ao seu humano para a liberdade e para a prática criativa de seu tempo. É preparar ao homem para viver em sociedade e isso se traduz para a educação cubana em uma nova relação ética do homem com a natureza e com os outros homens, numa imperiosa necessidade de formar a consciência em todos os cidadãos e nas novas gerações, em particular, a preservação a espécie humana; garantir a paz e a conviência entre os povos e nações; lograr a 
proteção do meio ambiente e uma filosofia de desenvolvimento sustentável nos cuidados da Mãe Terra.

\section{Conclusão}

Em sua essência, a investigação que deu origem a esse texto aponta que o processo educativo em Cuba não pode ser entendido sem o vínculo com as empreitadas históricas, que cunharam um imaginário de vertentes relativo às lutas de liberação, desde a época colonial. Cada acontecimento traz à luz a reação contra uma pretensa universalidade que vem de fora, de um mundo dominado ora por Portugal-Espanha, ora pela América do Norte ou, mais recentemente, pelas regras da globalização, reiterando nos cubanos um afã de originalidade e autoctonia, reforçado por sentimentos próprios da população cubana propensa a entrelaçar sua trajetória pessoal com a trama histórica do país, que oscila, entre o passado de lutas, o presente marcado por dificuldades e os interrogantes do futuro.

O sistema educativo, como pedra angular da Revolução Cubana, as imagens de Martí e de outros tantos heróis nacionais plasmadas na mente de sucessivas gerações, trazem à população de Cuba um diferencial que se caracteriza pelos sentimentos de autoconfiança e orgulho nacional - a "cubanía". Os mais de 150 anos marcados por fatos e homens, com sua carga de ensinamentos, fizeram com que a nação cubana tomasse consciência de que as contradições internas desencadearam a ingerência de forças expansionistas de potências estrangeiras. Frente a esse legado, os cubanos sentem desde algum lugar de si próprios um reclamo de honra insuflado pelos exemplos, uma vez que os jovens crescem ouvindo as narrativas das lutas contra o colonialismo. A formação do professor como militante político tem requerido, além dos saberes docentes, o preparo na qualidade de transmissor dos princípios basilares da Revolução. Entretanto, as convicções ideológicas não podem ser simplesmente ensinadas, mas devem ser adquiridas efetivamente pelos sujeitos mediante a interiorização de experiências significativas. Meras ações repetidas mecanicamente não devem ser encaradas como expressão de convicções no campo das ideologias, se essas não estiverem associadas ao enraizamento de atitudes conscientes.

Para entender a singularidade do processo é necessário ter em conta as condições políticas, econômicas e sociais do país na primeira metade do século XX, que determinaram a evolução das ideias socialistas e o seu entrelaçamento com a tradição patriótica do século XIX. A herança do neocolonialismo predatório impôs a unidade, como estratégia política. Como caráter prioritário de defesa, recorreu-se à educação para a construção de uma nova sociedade, porque as transformações pedagógicas, em suas complexidades, representavam a desagregação de antigas concepções herdadas dos contextos anteriores. Nos aportes educacionais da Revolução cubana percebe-se claramente a influência martiana, pela importância atribuída ao trabalho como princípio educativo, associadas das concepções de Marx. A necessidade de construir um novo referencial hegemônico, em contraposição às forças do passado, fez da educação e da revolução processos mutuamente inclusivos, numa intricada dialética, capaz de contemplar, simultaneamente, as concepções vindas do alto, devido ao caráter das alianças nos primeiros anos, e a pressão vinda de baixo, pela apropriação popular do processo revolucionário. 


\section{Referências}

AUGIER, Angel. Prólogo. In: MARTÍ, José. Versos sencillos. La Habana: Tertulia, 1961.

BARALT, Blanche Zacharie de. El Martí que yo conocí. La Habana: Centro de Estudios Martianos, 1990.

BUENAVILLA RECIO, Rolando. La Lucha del pueblo por una escuela cubana, democrática y progresista en la república mediatizada. La Habana: Pueblo y Educación, 1995a.

Historia da pedagogía en Cuba. La Habana: Pueblo y Educación, 1995b.

CANFUX GUTIÉRREZ, Jaime et al. La alfabetización: historia y autenticidad en Cuba. La Habana: Pueblo y Educación, 2006.

CHÁVEZ RODRÍGUEZ, Justo. Las Ideas de José Martí sobre educación. In: TURNER, Lidia et al. Martí y la educación. La Habana: Pueblo y Educación, 1996.

CIRULES, Enrique. O Império de Havana. São Paulo: Página Aberta, 1995.

COLECTIVO DE ESPECIALISTAS. Instituto Central de Ciencias Pedagógicas. Ministerio de Educación de Cuba. Pedagogía. La Habana: Pueblo y Educación, 1984.

COMISIÓN NACIONAL DE ALFABETIZACIÓN. Ministerio de Educación. Manual para el alfabetizador. La Habana: Imprenta Nacional de Cuba, 1961.

CUBA (República de). La Educación en Cuba. In: PEDAGOGÍA 99: Encuentro por la unidad de los educadores. La Habana, 1999.

DIRECCIÓN POLÍTICA DE LAS FAR. Historia de Cuba. La Habana: Consolidado de Artes Gráficas, 1967.

FARIÑAS LEÓN, Gloria. Desafios de la investigación educativa: presente y futuro. In: COLECTIVO DE AUTORES. Metodología de la investigación educacional. La Habana: Félix Varela, 2003. p.1-8.

GARCÍA RAMIS, Lisardo. El Modelo de secundaria básica en Cuba: fundamentos teóricos para su currículo. In: PEDAGOGÍA 2005. Encuentro por la unidad de los educadores. La Habana: 2005. (Curso Pre-evento)

Propuesta curricular para la escuela secundaria básica actual. La Habana: Pueblo y Educación, 2004.

GÓMEZ GUTIÉRREZ, Luis Ignacio. "Cuba: una revolución en la educación”. In: PEDAGOGÍA 2005. Encuentro por la unidad de los educadores. La Habana, 2005.

GUEVARA, Ernesto Che. El Socialismo y el hombre en Cuba. La Habana: Política, 1988. 
HART DÁVALOS, Armando. Ese mundo mayor es posible, si luchamos por él. In: Revista de la Sociedad Cultural José Martí. La Habana: Sociedad Cultural José Martí, n.13, 2005.

HERNÁNDEZ HERRERA, Pedro. Educación y televisión (Edutel): estamos donde estés. In: PEDAGOGÍA 2005. Resumen. La Habana, 2005

HERNÁNDEZ PARDO, Héctor. El Sol sobre las murallas. La Habana: Gente Nueva, 1983.

LABARRERE REYES, Guilhermina et al. Pedagogía. La Habana: Pueblo y Educación, 2002.

LEAL GARCÍA, Haydée. La Cultura histórica: elemento esencial en la concepción de la escuela cubana actual. In: GARCÍA RAMIS, Lisardo et al. Propuesta curricular para la escuela secundaria básica actual. La Habana: Pueblo y Educación, 2004. p.88-99.

MAKÁRENKO, Antón Semiónovich. Poema pedagógico. Moscú: Progresso, s/d.

MARTÍ, José. Obras Completas, Edición Crítica. La Habana: Centro de Estudios Martianos, 2011a.

. Ideário Pedagógico. La Habana: Centro de Estudios Martianos, 2011b.

. Obras completas. La Habana: Ciencias Sociales, 1975.

PIÑEIRO SUÁREZ, Nereyda et al. Algunas consideraciones sobre la teoría curricular y el aprendizaje del conocimiento histórico. Disponível em: <http://www.monografias.com/ trabajos30/teoria-curricular/teoria-curricular.shtml $>$. Acesso em: 23 fev.2006.

POGOLOTTI, Graziella. Palavras iniciais. Revista da Universidad de La Habana, n.245, p.5-6, 1995.

NUÑEZ MACHÍN, Ana. Cuba: primer país de América libre del analfabetismo. In: Revista Educación. La Habana: Pueblo y Educación, n.114, p.42-48, ene./abr. 2005.

REGO, Teresa Cristina. Vygotsky: uma perspectiva histórico-cultural da educação. Petrópolis: Vozes, 2002.

RODRÍGUEZ RIVERA, Guillermo. Por el camino del mar: los cubanos. La Habana: Boloña, 2005.

SARRACINO, Rodolfo. José Martí en el Club de Nueva York. Jalisco, Editorial Universidad de Guadalajara, 2010.

TABARES DEL REAL, José. La Contrarrevolución en el poder: 1952-1958. Revista da Universidad de La Habana, n.234, p.7-23, enero/abril 1989.

UNESCO. Educación para todos, el imperativo de la calidad: informe de seguimiento da la EPT en el mundo. Paris: Organización de las Naciones Unidas, 2005. 
VALLE LIMA, Alberto. "Exigencias y prioridades en el trabajo de la escuela cubana actual". In: PEDAGOGÍA 2013. Encuentro por la unidad de los educadores. La Habana, 2013.

VELÁZQUEZ COBIELLA, Ena Elsa. Educación para la vida: un desafío permanente a los sistemas educacionales de América Latina y del Caribe. In: PEDAGOGÍA 2013. Encuentro por la unidad de los educadores. La Habana, 2013.

VITIER, Cintio. Ese Sol del mundo moral. La Habana: Centro de Estudios Martianos, 2011. ${ }^{1}$ UNISANTOS
2 As referências escritas originariamente em Espanhol tem livre tradução realizada pela autora deste texto,
exceto em casos nos quais a tradução acarretaria a perda significativa da força de expressão própria do autor,
como em algumas citações de Martí.
${ }^{3}$ Segundo Rodríguez Rivera (2005, p.30) a cubanía é a consolidação da nacionalidade, o caráter insular
alicerçado desde as origens do país, que vem traçando pautas para atitudes da população cubana em todas as
épocas.
${ }^{4}$ Na madrugada de 10 de outubro de 1968 , o advogado Carlos Manoel de Céspedes, nascido em Bayamo
(Cuba), convocou seus escravos libertos à luta (VITIER, 2011, p.42).
${ }^{5}$ José Martí (1853 -1895) iniciou sua participação política escrevendo a jornais separatistas. Com a prisão de
seu mestre Rafael Mendive, cristalizou-se a atitude de rebeldia, que Martí nutria contra a dominação
espanhola. Em 1869 , foi condenado a seis anos de trabalhos forçados, mas passou somente seis meses na
prisão, pois conseguiu permutar a pena pela deportação à Espanha. Dedicou-se ao estudo do Direito, obtendo
o diploma em Filosofia e Letras na Universidade de Saragoza, no ano de1874. Entre 1881 e 1895 , viveu em
Nova Iorque, mas foi no México, na Guatemala e na Venezuela que alcançou o mais alto grau de
identificação com a autoctonia da América, até o momento desconhecido para um fillho de espanhol. Em
1882 , trabalhou para La Nación da Argentina. No comando de um contingente de cubanos, após breve
encontro com tropas espanholas no vilarejo de Dos Ríos, Martí foi atingido e seu corpo mutilado (SARRACINO, 2010).

${ }^{6}$ Mambí era o termo com que se denominava no século XIX aos insurretos contra Espanha nas guerras da independência de Cuba: ser mambí converteu-se, para os cubanos, em sinônimo de construtor do futuro, num reflexo de virilidade desmentida. "Horda de negros e vagabundos" foram expressões que tentaram resumir a carga emocional anticubana da metrópole sobre os mambizes (DIRECCIÓN POLÍTICA DE LAS FAR, 1967, p.480).

${ }^{7}$ Expressão de Versos Sencillos, escritos em 1891(MARTÍ, 1975, t.16, p. 67).

${ }^{8}$ Segundo Guevara (1988, p.16), "o homem novo alcançaria sua plena condição humana quando produzisse sem a compulsão da necessidade física de vender-se como mercadoria".

${ }^{9}$ Anton Semionovich Makárenko, professor na Ucrânia, país do leste europeu que no início do século XX era parte da antiga URSS, ajudou a repensar o papel da escola e da família na recém-criada sociedade comunista. Sua pedagogia tornou-se conhecida por transformar centenas de crianças e adolescentes marginalizados em cidadãos. No ano 1920, ainda jovem organizou uma colônia para meninos abandonadas, cujos pais haviam perecido durante a guerra civil, nas epidemias ou de fome, "meninos que o torvelinho das lutas havia arrastado por todos os caminhos da Rússia” (MAKÁRENKO, s/d, p. 2).

10 O bielo-russo Lëv Semënovich Vigotski (1896-1934) é o fundador da escola soviética de psicologia, principal corrente que, hoje, dá origem ao socioconstrutivismo. O contexto em que viveu Vigotski ajuda a explicar o rumo que seu trabalho iria tomar. Suas ideias, desenvolvidas na União Soviética emergente da Revolução Comunista de 1917, refletem o desejo de reescrever a psicologia com base no materialismo marxista e a de construir uma teoria da educação adequada ao mundo novo, egresso dos escombros da revolução. Não é exagero afirmar que, num certo sentido, a obra de Vigotski, Marx e Engels se completam (REGO, 2002, p. 100).

11 Permeado por câmbios em todas as esferas da sociedade, não somente econômicos, esse período foi desencadeado pelo desmoronamento do antigo campo socialista e pela extinção da URSS países com os quais o país mantinha relações comerciais que alcançavam um percentual significativo de aproximadamente $85 \%$, tanto na importação como na exportação. 